\title{
AC 2012-5558: COLLEGES BRING NUCLEAR TRAINING INTO THE COLLEGE CREDIT FOLD
}

Dr. Richard P. Coe, Thomas Edison State College

Richard P. Coe has more than 18 years experience in managing commercial nuclear training and education and the U.S. Department of Energy. He is currently Assistant Dean, nuclear engineering technology, at the Thomas Edison State College in Trenton, N.J. He has also served as a Senior Consultant in nuclear training and education to the International Atomic Energy Agency. 


\section{Colleges Bring Nuclear Training into the College Credit Fold}

In today's demanding environment nuclear energy technology has emerged as needing some of the most highly trained and educated personnel to assure safe and efficient operation of global energy production. Few industries can boast safer operation.

Highly technical training, accredited by strict national standards, has produced highly qualified workers who daily contribute to the ever growing global demand for cost effective energy.

Colleges responding to the growing demand for the need of nuclear energy personnel to secure college degrees have evaluated the foundation of commercial nuclear training and found a significant amount of college level credit. These nationally standardized curriculums have produced generic academic credit for all 104 operating US nuclear electric energy generating facilities. This credit when applied to technical degree study can bring a candidate very close to achieving what has become not only a job requirement but the basis for future advancement.

In 2011 Thomas Edison State College (TESC) did and in-depth review of 10 nuclear utility occupational positions training and qualification programs accredited by the National Academy for Nuclear Training. The positions ranged from operational to operational support positions. A TESC review team reviewed the training curriculums, instructional strategies, laboratory and simulator training, testing and instructor qualifications. The utility laboratory training process, and especially the on-the-job training (OJT) and training performance evaluation (TPE) processes were identified as being particularly well grounded academically and robust across the nuclear utility training programs. They are excellent examples of effective outcomes-based learning activities, and the qualification process ensures a thorough, effective assessment of learning outcomes. 
The results were compared to the courses required for a Bachelor of Science in Nuclear Engineering Technology and approved by the faculty Curriculum Committee. The following illustrates the amount of academic credit available to each nuclear utility occupational position:

- Shift Technical Advisor (STA) - 54 credits

- Senior Reactor Operator (SRO) - 60 credits

- Licensed Operator (LO) - 56 credits

- Non-Licensed Operator (NLO) - 36 credits

- Engineering Personnel (EP) - 29 credits

- Radiological Technician (RT) - 41 credits

- Chemistry Technician (CT) - 41 credits

- Electrician (E) - 28 credits

- Instrument and Control Technician (ICT) - 32 credits

- Maintenance Mechanic (MM) - 26 credits

- NRRPT Certification - 30 credits

- Passing NRC Generic Fundamentals Exam - 10 credits

- Navy Nuclear Training - 40 credits.

Thomas Edison State College also honors CLEP credits, Excelsior College Exam credits and its own TECEP Exam credits. Previous university/college study, from regionally accredited institutions, is also transferrable.

Prior Learning Assessment (PLA) is available for students who have learned college level knowledge outside the traditional classroom.

When a potential student applies for nuclear engineering or other technology degree the credit is automatically applied along with any other college level study. The result is a technical degree plan with the outstanding courses needed to complete the program.

The entire degree is on-line and more easily achievable than traditional degrees. Most of the students are full time working adults who find that this virtual option best fits their busy professional and family schedules. 